\title{
Diagnosis of right ventricular outflow obstruction in infants by cross sectional echocardiography
}

\author{
E D SILOVE, J V DE GIOVANNI, M F SHIU, MYINT MYINT YI
}

From the Children's Hospital, Ladywood Middleway, Birmingham

SUMMARY Cross sectional echocardiographic studies were assessed prospectively in 58 infants in whom right ventricular outflow obstruction was subsequently shown angiographically. A subcostal cut was used to display simultaneously the short axis of the aortic root and the long axis of the right ventricular outflow tract. This facilitated the differentiation of the common right ventricular outflow tract obstructive lesions. Tetralogy of Fallot was diagnosed correctly in 22 of 26 infants; pulmonary atresia with intact septum in all of 14 neonates; isolated severe pulmonary valve stenosis in all of nine infants; and pulmonary atresia with ventricular septal defect in eight of nine infants. The subcostal approach is the technique of choice for evaluating right ventricular outflow tract obstruction as it is more reliable than the left parasternal approach.

Patients with obstructive lesions of the right ventricular outflow tract often present in the neonatal period with profound cyanosis and hypoxaemia. They may present later if the obstruction is less severe or well compensated by another source of pulmonary arterial blood flow. Assessment of the nature of the lesion by cross sectional echocardiography may facilitate decisions concerning the timing of cardiac catheterisation, the type of surgical approach, and the preliminary use of $\mathrm{E}$ type prostaglandins.

The conventional echocardiographic approach to the diagnosis of right ventricular outflow tract obstruction has been the left parasternal short axis cut. ${ }^{1-3}$ We have found it unsatisfactory in small infants because: (1) the structures of interest being closest to the transducer are in the near field, the resolution of which is poor; and (2) it rarely allows visualisation of the entire right ventricular outflow tract, pulmonary valve, and pulmonary artery. We therefore prefer the subcostal window, which places the right ventricular outflow tract at an optimal distance from the transducer and allows the whole of the right heart to be displayed in its long axis. The purpose of this study was to determine whether each common lesion with right ventricular outflow tract obstruction could be diagnosed correctly. We investigated infants with tetralogy of Fallot, pulmonary

This study was supported in part by a grant from the Endowment Fund of the former United Birmingham Hospitals.

Accepted for publication 19 July 1983 atresia with ventricular septal defect, pulmonary atresia with intact ventricular septum, and isolated severe pulmonary stenosis.

\section{Patients and methods}

During two years we performed echocardiographic studies prospectively on 58 infants in whom the type of right ventricular outflow tract obstruction was subsequently shown by angiography. Twenty six infants had tetralogy of Fallot (aged 1 day to 11 months, mean 5 months), nine had pulmonary atresia and ventricular septal defect (aged 1 day to 6 weeks, mean 10 days), 14 had pulmonary atresia and an intact ventricular septum (aged 1 to 14 days, mean 3 days), four had isolated critical pulmonary stenosis (aged 1 to 7 days, mean 4 days), and five had severe isolated pulmonary valve stenosis, in whom right ventricular systolic pressure exceeded left ventricular pressure (aged 2 to 9 months, mean 5 months).

In all studies a mechanical sector scanner was used (Smith Kline Instruments, Ekosector I) with a 3.5 $\mathrm{MHz}, 30^{\circ}$ transducer. Whenever possible we routinely used all the subcostal, apical, and left parasternal cuts described by Tajik et al ${ }^{4}$ In addition to the right ventricular outflow tract we routinely assessed the atria and ventricles and their connections using subcostal and apical four chamber cuts. The presence or absence of ventricular septal defect was assessed by several routine views; the perimembranous subaortic defect most commonly associated with 


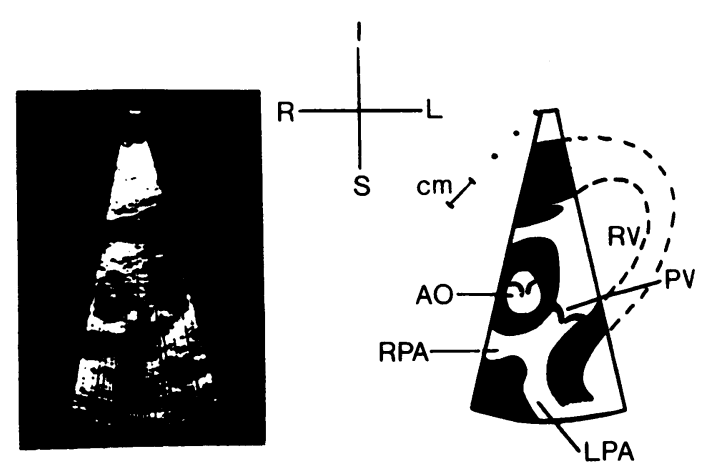

Fig. 1 Normal infant. Subcostal cut through short axis of aorta $(A O)$ showing the inlet of the right ventricle $(R V)$, pulmonary valve $(P V)$ in diastole, and pulmonary artery subdividing into right (RPA) and left (LPA) branches. I, inferior; $S$, superior; $R$, right; $L$, left.

tetralogy of Fallot was best seen in the long axis left parasternal and subcostal cuts.

The right ventricular outlet was routinely displayed as follows. In the standard subcostal long axis cut the left ventricular outlet and outlet septum were displayed together with the aortic valve and ascending aorta. Slight anterior orientation with further clockwise rotation showed the whole of the ascending aorta and the first two parts of the arch (when left sided). The transducer was then rotated anticlockwise through about $90^{\circ}$ with slightly more anterior angulation so that the aortic root at valve level was seen in its short axis. This cut displayed simultaneously the long axis of the pulmonary valve, the main pulmonary artery and branches, the immediate subpulmonary region, the right ventricular cavity, and the tricuspid valve "en face" (Fig. 1). Slight posterior angulation cutting across the short axis of the left ventricle sometimes improved the display of the right ventricular infundibulum.

The accuracy and reliability of the echocardiographic assessment of the components of each lesion were determined by comparison with the subsequent angiograms.
Results (Table)

TETRALOGY OF FALLOT (26 infants)

The echocardiographic criteria for the diagnosis of tetralogy of Fallot were as follows: normal inlets of the heart, two ventricles with normal morphology, a perimembranous outlet subaortic ventricular septal defect with aortic override, narrowing of the pulmonary valve and right ventricular infundibulum, and the presence of a main pulmonary artery with right and left branches. In all 26 infants the ventricular septal defect was correctly diagnosed using the long axis subcostal and left parasternal cuts and the aorta was shown overriding the septum. In the subcostal cut, which displayed the short axis of the aortic root and valve, the long axis of the right ventricular outflow tract was visualised in all but two of the early cases in the series (Fig. 2). In all 24 patients in whom the right ventricular outflow tract was shown the main pulmonary artery and its branches were seen. In most cases the pulmonary arteries were much smaller than the enlarged aortic root. The pulmonary valve was seen to open in systole from a closed diastolic position

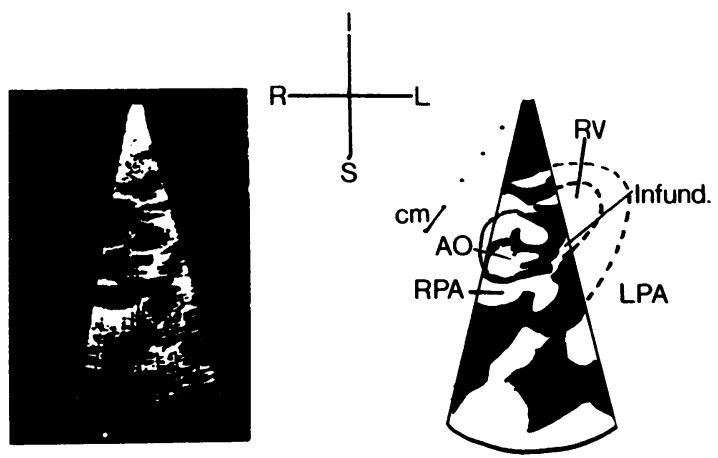

Fig. 2 Infant with tetralogy of Fallot. Subcostal cut through short axis of aorta showing narrow right ventricular infundibulum (Infund) leading to small pulmonary valve opening then to good size pulmonary arteries. For other abbreviations see Fig. 1 .

Table Right ventricular outflow tract obstruction in 58 infants

\begin{tabular}{llccl}
\hline Type of obstruction & Age & No. of patients & \multicolumn{2}{c}{ Echocardiography } \\
\cline { 3 - 5 } & & Correct & Failure \\
\hline Tetralogy of Fallot & 1 day - 11 months & 26 & 22 & 2 (not visualised) \\
PAt, VSD & 1 day - 6 weeks & 9 & 8 & (PAt, VSD) \\
PAt, IVS & $1-14$ days & 14 & 14 & 0 \\
PS, critical & $1-7$ days & 4 & 4 & 0 \\
PS, severe & $2-9$ months & 5 & 5 & 5 \\
\hline Totals & & 58 & 53 & 0 \\
\hline
\end{tabular}

PAt, pulmonary atresia; IVS, intact ventricular septum; PS, pulmonary stenosis; VSD, ventricular septal defect. 


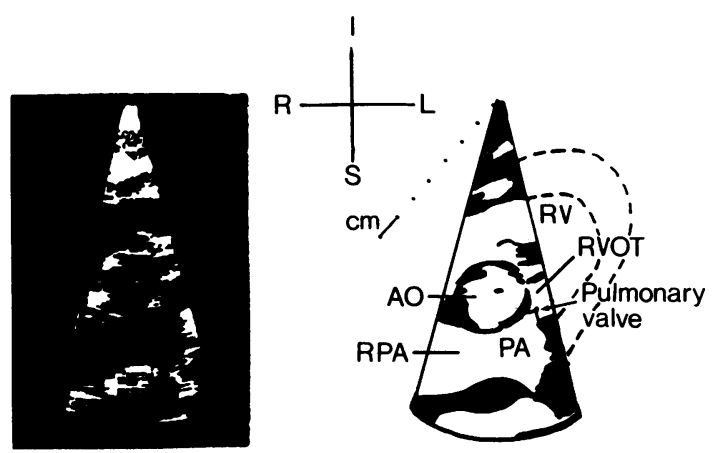

Fig. 3 The same subcostal cut as in Fig. 1 in infant with tetralogy of Fallot and dysplastic pulmomary valve. The right ventricular outflow tract ( $R V O T)$ leads to a narrow valve ring beyond which the pulmonary artery $(P A)$ is dilated and the RPA is aneurysmal, measuring $3 \mathrm{~cm}$ in diameter. For other abbreviations see Fig. 1.

in 22 infants; in two we were unable to detect pulmonary valve opening and they were wrongly diagnosed as cases of pulmonary atresia. In two infants with dysplastic pulmonary valves the pulmonary arteries were considerably dilated (Fig. 3). All 24 infants had narrowing of the subpulmonary infundibulum, which was seen in many by the cuts just described, but in others by slight posterior angulation of the transducer, cutting through the short axis of the left ventricle.

\section{PULMONARY ATRESIA WITH VENTRICULAR SEPTAL}

DEFECT (nine infants)

The criteria for diagnosing pulmonary atresia with ventricular septal defect were similar to those for tetralogy of Fallot except for the finding of an atretic pulmonary valve and, in some cases, of atretic pulmo-

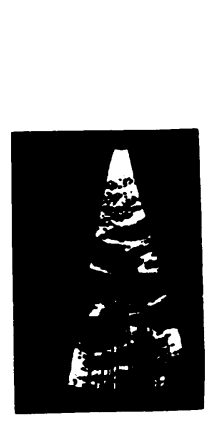

SYSTOLE
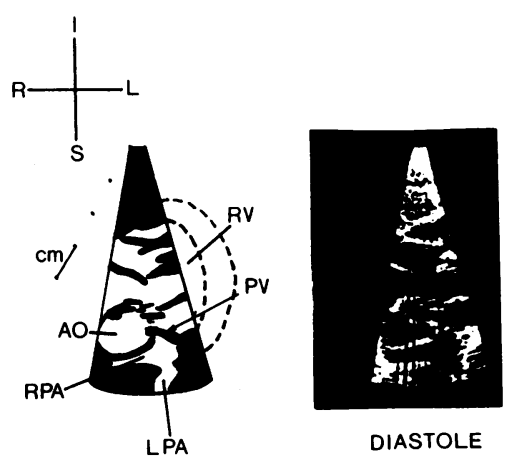

DIASTOLE

Fig. 4 The same subcostal cut as in Fig. 1 in neonate with pulmonary atresia and intact septum. The pulmonary valve, seen as an echo dense bar between the right ventricle and pulmonary artery, moves towards the pulmonary artery during systole but does not open. For abbreviations see Fig. 1.

Silove, de Giovanni, Shiu, Yi

nary arteries. By means of the long axis subcostal and left parasternal cuts the ventricular septal defect was correctly diagnosed in all nine infants, and aortic override was shown.

In eight of the nine infants the subcostal right ventricular long axis cuts showed an echo dense bar in the region of the pulmonary valve at the end of the right ventricular infundibulum. It was most clearly seen in seven infants, in whom the main pulmonary artery could be identified. In two infants there was no evidence of a main pulmonary artery. Pulmonary valve motion occurred in four cases, indicating the presence of an imperforate valve, but opening of the valve was not seen. The systolic motion was interpreted as valve opening in one case, which was therefore incorrectly diagnosed as tetralogy of Fallot. The main pulmonary artery was minute in five of the seven cases in which it was visualised. A right pulmonary artery, branching from the main pulmonary artery, was identified in six cases and a left pulmonary artery in five. In one of the two infants with no visible main pulmonary artery a small right pulmonary artery was seen peripherally, and, retrospectively, the left pulmonary artery was identified arising anomalously from the ascending aorta; but in the other infant no distal pulmonary arteries could be seen.

\section{PULMONARY ATRESIA WITH INTACT}

VENTRICULAR SEPTUM (14 infants)

The important echocardiographic finding in pulmonary atresia with intact ventricular septum was an echo dense bar in the region of the pulmonary valve separating the subpulmonary infundibulum from the main pulmonary artery. It was present in all 14 infants and was best shown in the subcostal right ventricular long axis plane, in which the aortic root was seen in its short axis. In almost every case the bar probably rep-

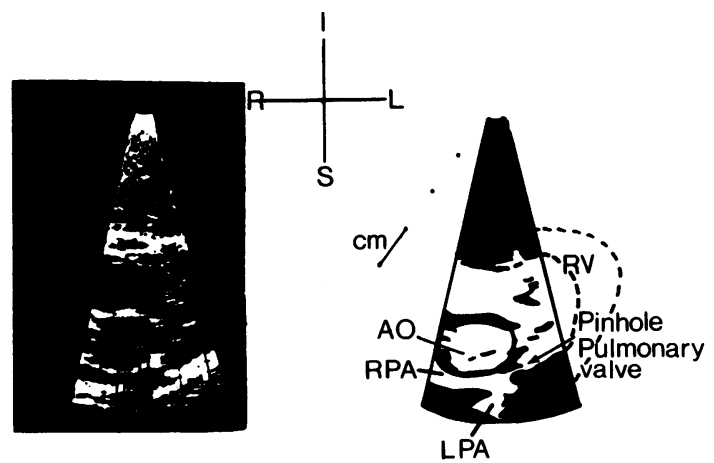

Fig. 5 The same subcostal cut as in Fig. 1 in neonate with critical pulmonary valve stenosis. Note the thickened pulmonary valve leaflets with a narrow opening leading from a small right ventricle to a small pulmonary artery. For abbreviations see Fig. 1. 
resented an imperforate pulmonary valve because its direction of movement during the cardiac cycle corresponded to the motion of the pulmonary valve, but there was no true opening during systole (Fig. 4). The main pulmonary artery and branches were usually clearly seen and were usually normal in size. The right ventricular infundibulum was invariably narrowed. This cut was also favourable for displaying the size and motion of the tricuspid valve. The conventional four chamber cuts helped to confirm that the tricuspid valve was smaller than the mitral valve and the right ventricle had a small cavity and thickened wall. The right atrium was generally larger than the left, the atrial septum bulging into the left atrial cavity and the borders of the foramen ovale making a distinct flapping motion into the left atrium, consistent with a patent foramen ovale with right to left shunting.

\section{PULMONARY VALVE STENOSIS (nine infants) (Fig. 5} and 6)

The echocardiographic diagnosis of pulmonary valve stenosis was made when the pulmonary valve was closed in diastole and narrowly open in systole. It was best displayed in the subcostal right ventricular long axis plane when the aortic root was seen in the short axis. In all nine infants we found a narrow valve opening with thickening of the valve leaflets and poststenotic dilatation of the pulmonary artery. The right ventricular cavity of the four neonates with critical pulmonary stenosis was smaller than normal in three and normal in the fourth but was enlarged in the five older infants with severe pulmonary stenosis. In all nine infants we showed normal inlets of the heart, normal ventricular morphology, and an intact ventricular septum.

\section{Discussion}

This study suggests that the components of the right ventricular outflow tract can be reliably shown by

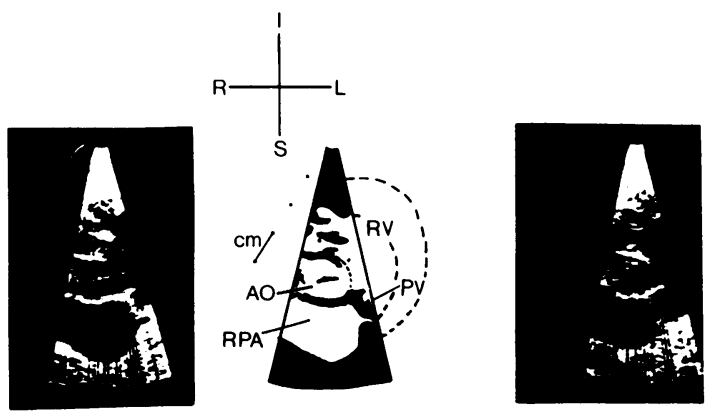

Fig. 6 The same subcostal cut as in Fig. 1 in infant with severe pulmonary valve stenosis. The pulmonary valve ring is narrow (seen best in diastole on left) and the valve does not open completely in systole (right). There is poststenotic dilatation of the pulmonary artery. For abbreviations see Fig. 1. echocardiography in infants when a subcostal short axis plane is used. This is a cut across the short axis of the aortic root and valve displaying the whole of the right ventricular outflow in its long axis and the tricuspid valve, which is seen "en face", opening from the right atrium to the right ventricle. The sizes of the body and infundibulum of the right ventricle can be assessed in this plane, which is approximately at right angles to the conventional long axis plane and $30^{\circ}-40^{\circ}$ anterior to the four chamber plane. The pulmonary valve, main pulmonary artery, right pulmonary artery, and often the left pulmonary artery are also seen in this single cut. The subcostal short axis plane described previously by others ${ }^{4}$ cuts across the structures more posteriorly and shows the left ventricle in short axis together with part of the long axis of the right ventricular outflow, but the pulmonary arteries are not usually well displayed.

Other workers have advocated and used the left parasternal approach for evaluating isolated pulmonary valve stenosis, ${ }^{5}$ tetralogy of Fallot, and pulmonary atresia with ventricular septal defect. ${ }^{367}$ The left parasternal short axis cut of the aortic root or the left ventricle may display the long axis of the right ventricular outflow tract, but limited information seems to have been obtained. For example, Hagler et al. ${ }^{7}$ recorded the pulmonary valve in only $63 \%$ of their patients with tetralogy of Fallot (mean age 8.7 years). Caldwell et al. ${ }^{3}$ succeeded in 26 of 29 patients with tetralogy of Fallot, but only four of these were infants. Weyman et al. ${ }^{5}$ recorded the pulmonary valve in 20 of 22 patients with pulmonary valve stenosis using the left parasternal approach, but identified more than one pulmonary valve cusp in only $64 \%$ of their cases.

In our own experience using the $3.5 \mathrm{MHz} 30^{\circ}$ transducer the left parasternal approach was unsatisfactory for evaluating the right ventricular outflow tract. The structures of interest were then the most anterior and therefore closest to the transducer, requiring good near field resolution for accurate evaluation. They were also those closest to the apex of the $30^{\circ}$ sector and could not be displayed in a single frame but only by scanning the transducer continuously along their length. In the small infant the right ventricular outflow tract was optimally displayed by the subcostal approach, when it was about $5 \mathrm{~cm}$ from the transducer and in the broad fan of the sector. This approach had another important advantage. It enabled visualisation not only of the right ventricular outflow tract and of the pulmonary artery and branches but also of the inlet and long axis plane of the right ventricle. It provided a picture similar to that obtained by a right ventriculogram in the right anterior oblique projection.

In patients with pulmonary atresia and ventricular septal defect we had some difficulty in identifying all 
the structures. It was most important to ensure that the transducer was angled sufficiently anteriorly for the sector plane to cut across the aortic root transversely and simultaneously display the right ventricular infundibulum. We found a blind right ventricular outflow tract in all these patients, differentiating them from patients with persistent truncus arteriosus. The latter diagnosis may be made incorrectly, even at angiography, if either the main pulmonary artery trunk or the blind right ventricular outflow tract cannot be identified. ${ }^{8}$ We also found this plane helpful in recognising the right and left pulmonary arterial branches. Perhaps the suprasternal notch approach might prove more suitable for identifying continuity of the main pulmonary artery with its branches. ${ }^{9}$

This study has shown that the types of right ventricular outflow tract obstruction may be differentiated with reasonable accuracy by a subcostal echocardiographic cross section which simultaneously displays the short axis of the aortic root and the long axis of the right ventricle and the pulmonary arteries. It is of particular value in the neonate, in whom treatment with $\mathrm{E}$ type prostaglandins can be started before planning the cardiac catheterisation and either palliative or corrective surgery.

We thank Mrs Margaret Miles and Mrs Rosemary Edgar for their meticulous technical assistance.

\section{References}

1 Maron BJ, Henry WL, Griffith JM, Freedom RM, Kelly DT, Epstein SE. Identification of congenital malformations of the great arteries in infants by real-time twodimensional echocardiography. Circulation 1975; 52: 671-7.
2 Sahn DJ, Terry R, O'Rourke R, Leopold G, Friedman WF. Multiple crystal cross-sectional echocardiography in the diagnosis of cyanotic congenital heart disease. Circulation 1974; 50: 230-8.

3 Caldwell RL, Weyman AE, Hurwitz RA, Girod DA, Feigenbaum H. Right ventricular outflow tract assessment by cross-sectional echocardiography in tetralogy of Fallot. Circulation 1979; 59: 395-402.

4 Tajik AJ, Seward JB, Hagler DJ, Mair DD, Lie JT. Two-dimensional real-time ultrasonic imaging of the heart and great vessels. Technique, image orientation, structure identification, and validation. Mayo Clin Proc 1978; 53: 271-303.

5 Weyman AE, Hurwitz RA, Girod DA, Dillon JC, Feigenbaum H, Green D. Cross-sectional echocardiographic visualisation of the stenotic pulmonary valve. Circulation 1977; 56: 769-74.

6 Lange LW, Sahn DJ, Allen HD, Goldberg SJ. Subxiphoid cross-sectional echocardiography in infants and children with congenital heart disease. Circulation 1979; 59: 513-24.

7 Hagler DJ, Tajik AJ, Seward JB, Mair DD, Ritter DG. Wide-angle two-dimensional echocardiographic profiles of conotruncal abnormalities. Mayo Clin Proc 1980; 55: 73-82.

8 Smallhorn JF, Anderson RH, Macartney FJ. Two dimensional echocardiographic assessment of communications between ascending aorta and pulmonary trunk or individual pulmonary arteries. $\mathrm{Br}$ Heart $\mathrm{f}$ 1982; 47: 563-72.

9 Huhta JC, Piehler JM, Tajik AJ, et al. Two-dimensional echocardiographic detection and measurement of the right pulmonary artery in pulmonary atresiaventricular septal defect: angiographic and surgical correlation. Am F Cardiol 1982; 49: 1235-40.

Requests for reprints to Dr Eric D Silove, Children's Hospital, Ladywood Middleway, Birmingham B16 $8 \mathrm{ET}$. 